Annuaire suisse de politique de développement

1 | 1981

Annuaire Suisse - Tiers Monde 1981

\title{
4. Appendice
}

\section{Antoine Brawand}

\section{OpenEdition}

\section{Journals}

Édition électronique

URL : http://journals.openedition.org/aspd/1126

DOI : $10.4000 /$ aspd. 1126

ISSN : 1663-9669

\section{Éditeur}

Institut de hautes études internationales et du développement

\section{Édition imprimée}

Date de publication : 1 janvier 1981

Pagination : 327-331

ISSN : 1660-5934

\section{Référence électronique}

Antoine Brawand, «4. Appendice», Annuaire suisse de politique de développement [En ligne], 1 | 1981, mis en ligne le 23 janvier 2013, consulté le 08 septembre 2020. URL : http://journals.openedition.org/ aspd/1126 ; DOI : https://doi.org/10.4000/aspd.1126 


\section{APPENDICE}

\subsection{Sigles et signes utilisés, remarques}

Principaux sigles :

\begin{tabular}{|c|c|}
\hline AELE & Association européenne de libre-échange \\
\hline APD & Aide publique au développement \\
\hline BFS & Bureau fédéral de statistique \\
\hline BNS & Banque nationale suisse \\
\hline CAD & Comité d'aide au développement (OCDE) \\
\hline CEE & Communauté économique européenne \\
\hline CNUCED & $\begin{array}{l}\text { Conférence des Nations Unies sur le commerce } \\
\text { et le développement }\end{array}$ \\
\hline DDA & $\begin{array}{l}\text { Direction de la coopération au développement et de l'aide } \\
\text { humanitaire (Département fédéral des affaires étrangères) }\end{array}$ \\
\hline OCDE & Organisation de coopération et de développement économiques \\
\hline OFAEE & $\begin{array}{l}\text { Office fédéral des affaires économiques extérieures } \\
\text { (Département fédéral de l'économie publique) }\end{array}$ \\
\hline PIB & Produit intérieur brut \\
\hline PNB & Produit national brut \\
\hline
\end{tabular}

Signes :

$\begin{array}{ll}0,0 & \text { Nul ou négligeable } \\ - & \text { Non disponible } \\ \text { n.a. } & \text { Non applicable } \\ \mathrm{p} & \text { Provisoire }\end{array}$

Remarques :

- Les chiffres exprimés en unités monétaires (francs suisses ou dollars) correspondent à des montants nominaux. Ils sont généralement accompagnés de pourcentages ou de ratios permettant de mieux comprendre la structure de l'objet d'étude.

- Les chiffres étant arrondis, les totaux ne correspondent pas toujours à la somme des composants. 
- Les marges d'erreur sont généralement bien supérieures au degré d'arrondissement des chiffres. Ceux-ci résultent souvent d'approximations ou d'enquêtes menées auprès d'un nombre restreint d'agents économiques. Même lorsqu'en principe l'enregistrement des opérations est complet, une partie d'entre elles échappe généralement aux statistiques.

\title{
4.2. Composition des groupes de pays
}

II n'existe pas de classification unique pour les statistiques des flux commerciaux, financiers et d'aide au développement. Chaque organisation internationale tend à définir ses propres catégories. Pour le commerce, nous nous sommes fondés sur la classification établie par la CNUCED sur la base du système défini par le Bureau de statistique des Nations Unies. Concernant les flux financiers et l'aide publique au développement, nous avons retenu la classification du Comité d'aide au développement (CAD) de I'OCDE. Le haut degré d'agrégation de certaines données fournies par le CAD ne permet pas de les classer différemment. Cette situation nous a donc obligés à adopter deux classifications distinctes, l'une pour la première section (commerce) (1), I'autre pour les deux autres sections (flux financiers et aide publique au développement).

\author{
A. Statistique du commerce international \\ a) Classification générale : \\ Pays développés à économie de marché : \\ Europe : \\ Comprend les pays de la CEE, de l'AELE, l'Espagne, Gibraltar, la Grèce \\ (désormais membre de la CEE) et la Yougoslavie. \\ Outre-mer : \\ USA, Canada, Japon, Israël, Australie, Nouvelle-Zélande, Afrique du \\ Sud. \\ Pays socialistes d'Europe : \\ Comprend les pays européens membres du COMECON et l'Albanie. \\ Pays socialistes d'Asie : \\ Comprend la Chine, la Corée du Nord, la Mongolie et le Vietnam. \\ Pays du Tiers Monde : \\ Voir classification géographique.
}

1. Les statistiques du commerce international publiées par l'OCDE sont elles-mêmes classées selon des catégories différentes de celles du CAD ! 


\section{b) Classification géographique des pays du Tiers Monde}

\section{Afrique :}

Tous les pays sauf I'Afrique du Sud.

\section{Amérique :}

Tous les pays sauf les USA et le Canada.

Asie :

Tous les pays sauf le Japon, Israël, la Chine, la Corée du Nord, la Mongolie et le Vietnam, mais y compris la Turquie et Chypre.

\section{Divers :}

Tous les pays d'Océanie sauf I'Australie et la Nouvelle-Zélande.

Un pays européen : Malte.

\section{c) Classification économique des pays du Tiers Monde (établie par la CNUCED)}

Principaux pays exportateurs de pétrole :

Ce groupe comprend les pays dont les exportations de pétrole et de produits pétroliers ont représenté plus de $50 \%$ de leurs exportations totales en 1974. Ces pays sont les suivants : Algérie, " Angola, ${ }^{*}$ Bahreïn, ${ }^{*}$ Brunéi, Equateur, Gabon, Indonésie, Iran, Irak, Koweït, Libye, Nigéria, ' Oman, Qatar, Arabie saoudite, ${ }^{*}$ Trinité-et-Tobago, Emirats arabes unis et Vénézuéla. (Les noms des pays non-membres de I'OPEP sont précédés d'un astérisque.)

Pays exportateurs d'articles manufacturés à croissance rapide :

Ce groupe comprend les pays dont les exportations d'articles manufacturés ont dépassé 800 millions de dollars en 1976 et dont le taux d'accroissement annuel moyen (nominal) des exportations d'articles manufacturés a dépassé $20 \%$ durant la période de 1967 à 1976. Il s'agit des pays suivants : Argentine, Brésil, Hong-Kong, Corée du Sud, Mexique, Singapour et Taïwan. (Ce dernier territoire ne figure pas dans la liste de la CNUCED mais nous I'avons rajouté.)

\section{Autres pays :}

Tous les pays ou territoires du Tiers Monde non compris dans les deux groupes précédents.

Pour la population, le produit intérieur brut et le commerce extérieur des différents groupes de pays, voir point 1.5. "Statistiques de référence".

\section{B. Statistiques des flux financiers et de l'aide publique au développement}

\section{a) Pays membres du Comité d'aide au développement (CAD)}

République fédérale d'Allemagne (RFA), Australie, Autriche, Belgique, Canada, Danemark, Etats-Unis d'Amérique, Finlande, France, Italie, Japon, Norvège, Nouvelle-Zélande, Pays-Bas, Suède, Suisse et Royaume-Uni. 
b) Pays en voie de développement

Europe :

Portugal, Espagne, Gibraltar, Malte, Yougoslavie, Grèce, Chypre et Turquie.

Afrique :

Tous les pays sauf I'Afrique du Sud.

Amérique :

Tous les pays sauf USA et Canada.

Asie :

Tous les pays sauf Japon, URSS, Mongolie, Corée du Nord et Turquie.

Océanie :

Tous les pays sauf Australie et Nouvelle-Zélande.

Les listes des pays en développement d'Afrique, d'Amérique et d'Océanie correspondent à la classification géographique retenue pour le commerce international.

\subsection{Principales sources}

\section{a) Publications suisses}

BNS -- Les banques suisses en 19.., Zurich, Orell Füssli Verlag (parution annuelle).

BNS -- Bulletin mensuel, Zurich.

DIRECTION GENERALE DES DOUANES - Statistique annuelle du commerce extérieur de la Suisse, Berne.

DDA - La coopération suisse au développement, Bulletin de statistiques, Berne (parution annuelle).

OFAEE - Memorandum de la Suisse au Comité d'aide au développement, Berne (document établi annuellement).

b) Publications d'organisations internationales

CNUCED - Manuel de statistiques du commerce international et du développement, New York, Nations Unies (paraît avec un supplément annuel).

OCDE - Statistiques du commerce extérieur, Série A, Bulletin mensuel, Paris. 
OCDE - Coopération pour le développement, Efforts et politiques poursuivis par les membres du Comité d'aide au développement, Examen 19.., Paris (parution annuelle).

OCDE -- Répartition géographique des ressources financières mises à la disposition des pays en développement, 1976-1979, Paris, 1980. 